\title{
Economic Performance of Goat Breeds Farming Sustainability and Policy Analysis
}

\author{
Kheiry Hassan M. Ishag \\ Dhofar Cattle Feed Company - P.O. Box 1220 - PC 211 - Sultanate of Oman
}

\begin{abstract}
The goat (Caprus hircus) farming is considered as important animal husbandry activities in Oman and represents $64 \%$ of the total animal population. Most of goat are located in Sharqiyah and Batinah Region and contain 50\% of total goat of the country. Dry Mater nutrient requirement for goat animal is about 35\% of the total Dry Mater nutrient requirement. Goat production systems in Oman can be classified to three production systems i.e. traditional mounting pasture system, goat and sheep husbandry at farms located at costal area and modern goat production systems at new established farms. Due to low performance of local breed and high cost of inputs the Government introduced animal feed subsidy program and reduce goat feed price by $14 \%$. The Government stopped Rhodes Grass cultivation at costal area due to water shortage and water and soil salinity increased. The study use (SERF) techniques to investigate the effect of new policies on goat farming viability and aims to identify the most sustainable goat farming system. The Modern Goat Farming found as the most risk efficient goat farming system and preferred to other systems. Risk premium price of RO 35.930 per Does is required to persuade farmers to shift from traditional goat farming to high yield breed and modern goat farming system. Policy Makers need to pay RO 25.290 per Does to compensate farmers at semiintensive coastal goat farming system to stop growing Rhodes Grass and improve ecosystem resilience and economic viability.

Key words: Stochastic Efficiency with Respect to a Function (SERF), farming system, risk efficient, simulation model, goat breed, resilience ecosystem, sustainability.
\end{abstract}

\section{Introduction}

Oman is located at $\left(15-27^{\circ}\right)$ north latitude with long summer season extended for six months and warm winter and low rain fall. The total animal population as per year 2013 censes account for 3.236 Million and goat population is estimated of 2.085 Million, which represent $64 \%$ of the total animal population. The most of goat are in Sharqiyah 26\% and Batinah region 24\% as per year 2013 censes and required about 35\% of the total Dry Mater nutrient requirement in Oman.

The goat (Caprus hircus) farming is considered as the important agricultural activities in Oman especially in mountainous and semi-mountainous areas where pastureland is available and low intensive systems are present. Goat production systems in North Oman can be classified to three production systems i.e. traditional mounting pasture system, goat and sheep husbandry at farms located at costal area and modern goat production systems at new established farms.

The traditional mounting pasture goat husbandry system located inside land and depends mainly on grazing. Because of the low nutritional quality of the pasture plants, the growth and production of goats in traditional systems appears to be limited. The natural vegetation of the mounting pasture provides $50-60 \%$ of daily feed required and supplement feed such as dates, dried sardine fish and grass are offered, Eva Schlecht et al. (2009).

Farmers at costal area at Sharqiyah and Batinah Regions breed goat and sheep at their farms and feed forage crops such as alfalfa, grass, crop residuals, dates and dried sardines fish and only surplus and excess goat products sold to the local market. However, this type of production system generates a very low profit as farmer could not offer sufficient animal feed to his animal from his own pocket. Farmers in this goat farming system engaged in Government jobs and other economic activity not related to farming to cope with yield and price risk.

Few farmers practices modern intensive goat production systems and benefited from latest technologies such as high yield breed, modern irrigation system, mechanization and readymade animal feed. Farmers manage to sell the goats at Religious holidays and Eid Occasion with a good price and gain good profits.

Zaibet et al. (2004) studied the modern goat production systems on Al Jabal al Akhdar and found that output is increasing with increasing input by non-farm income and purchased feed, but that both are used rather inefficiently, resulting in decreasing returns-to-scale. To improve goat farming adequate production level should be obtained by using all resources in an optimal way and good input output ratio need to be maintained.

The Livestock Research Centers located in Rumais established with objectives to conserve indigenous animal breeds such as goats, sheep and cattle and to improve animal strains. There is a clear and intensive 
selection program to improve the genetic potential for the local breeds in different species. Damascus (Shami) goats breed introduced at Rumais Livestock Research Centers to evaluate breed performance. An experiment research and on farm trails implemented to examine breed performance under Batinah Region ecological and farming system. The experiment compared economic performance of Damascus (Shami) goats breed with Batinah goat breed.

\section{Problem statement:}

Goat farming is the most dominant animal husbandry in Oman and goat population account $64 \%$ of the total Oman animal population. Farmers involved in goat farming constitute $44 \%$ of the total livestock holding farmers. Due to low performance of local breed and high cost of feed and inputs the Government introduced animal feed subsidy program in year 2011 and reduce goat feed price by $14 \%$. The Government Authorities stopped Rhodes Grass (Chloris gayana) cultivation at Batinah costal area in year 2005 due to water shortage, inefficient irrigation water used and water and soil salinity increased. The study investigate the effect of new policies such as feed subsidy program, home grown forage and goat breed performance on goat farming viability and aims to identify the most sustainable goat farming system. The study evaluated alternatives risk efficient policies implemented by Government Authority to support goat farming systems and improve production and business profitability.

\section{Literature review:}

Investment in goat farming needs a long term investment decision with uncertain milk yield and meat production and market price. The goat farming practices sustainability should insure system ability to maintain productivity in spite of major constrains and disturbance. Goat farming Net Return and financial viability can be taken as a measurement to choice between goat breed farming system and policy alternative, Lien G. et.al (2007). Stochastic and dynamic nature of goat breed farming can be model and probability of getting positive Net Return for each policy and goat farming system can be calculated.

Monte Carlo Simulation dynamic model for business net return under risk and uncertainty was addressed by many researchers. The dynamic analysis provided a range of outcomes that can reduce the risk of revenue and inputs cost uncertainty and give more reliable results for farmers and policy advisers. The stochastic efficiency analysis and technique can rank alternative goat breed, agriculture policy and goat farming system over a range of risk aversion level. This technique developed by Hardaker et al. (2004a) and called stochastic efficiency with respect to a function (SERF). Gregory K. et al. (2012) used SERF to evaluate genetically modified maize in South Africa. SERF is based on the notion that ranking risky alternatives in terms of utility which is the same as ranking alternatives with certainty equivalents (CE). The certainty equivalent is defined as the sure sum with the same utility as the expected utility of the risky prospect, Hardaker et al., (2004b). Irene Tzouramani et.al (2011) used stochastic efficiency with respect to a function (SERF) to explore economic viability of conventional and organic sheep farming in Greece and found both conventional and organic sheep farming are viable.

In this study, (SERF) technique is applied to assess a set of alternative goat farming policies. SERF also used to rank and compare level of decision maker preferences including risk neutral, normal and moderate risk averse, J. W. Richardson et al. (2008). Goat performance data, milk yield and meat production for each got breed were collected from Rumais Livestock Research Centers and on farm trail experiment conducted on year 2005 at Batinah Region. The business revenue and input cost were calculated for each goat breed and goat farming system. Six stochastic simulation models were employed to estimate net return distribution. The main objective of this paper is to investigate sustainability of goat farming system and recognize the most risk efficiency one over a range of risk aversion level.

\subsection{Net Return}

\section{Methodology}

The evaluation of goat farming depends on estimation income and cost values to calculate business net return with uncertain outcome given the stochastic yields, price and variable cost. The probability range of net return with relative preference and utilities of decision makers need to be considered for economic evaluation of goat farming system and risk efficiency study.

Six stochastic simulation models were used to incorporate risk of uncertain variable in the model and reduce all possible risky alternatives to small number of alternatives. The Net Return for each model is calculated by identifying key parameters and variables and subtracting the variable and fixed cost from the revenue. 


\subsection{Monte Carlo Simulation}

Monte Carlo simulation is a computational algorithm designed to evaluate the variability or stochastic of the input variables of a model. It can be used to model the effects of key variables on the Net Return of a given proposal. The process involves identification and assessment of the key variables. For each key variable, we fit a probability density function that best describes the range of uncertainty around the expected value.

The model including these variables is then calculated using randomly-generated input values taken from the underlying probabilistic distribution function. The computer model combines these inputs to generate an estimated outcome value for (NR) and process is repeated (five thousand times). Monte Carlo simulation model is currently recorded as the most powerful technique for business net return analysis, Kheiry (2015). It is useful when there are some variables are significantly uncertain. The @ Risk 7.5.0 from (Palisade Corporation, Ithaca, New York) add-in for Excel was used to calculate the stochastic nature of key variables in the Monte Carlo simulation model. The main parameters and cost used are presented in Table (1).

Table (1) : Batinah and Shami Goats Breeds Parameters and Sale Price in Batinah Region :

\begin{tabular}{|l|l|l|l|}
\hline Parameters & Batinah Breed & Shamin Breed & \% Changes \\
\hline No. Kids born from 100 Does @ Research & 140 & 158 & $12.85 \%$ \\
\hline No. Kids born from 100 Does @ Farmers & 104 & 118 & $13.46 \%$ \\
\hline No. Bucks (Males) sold & 52 & 59 & $13.46 \%$ \\
\hline No. Does (Females) sold & 32 & 39 & $21.87 \%$ \\
\hline Daily growth rate per grams & 91 & 109 & $19.78 \%$ \\
\hline Milk yield per day & 0.380 & 0.810 & $131.57 \%$ \\
\hline Milking days & 180 & 240 & $133.33 \%$ \\
\hline Breeding days & 198 & 165 & $-16.67 \%$ \\
\hline & & & \\
\hline Bucks (Male) sale price per head & 120 & 100 & $-16.66 \%$ \\
\hline Does (Female) sale price per head & 100 & 85 & $-15.00 \%$ \\
\hline Cull Does sale price per head & 35 & 30 & $-14.28 \%$ \\
\hline No. Milking Does & 96 & 95 & $-0.100 \%$ \\
\hline Total milk sale /days & 120 & 180 & $50.00 \%$ \\
\hline Total milk sold/head/kg & 45.6 & 145.8 & $119.00 \%$ \\
\hline Total milk revenue & 1532 & 4848 & $116.44 \%$ \\
\hline Total Revenue & 10818 & 13964 & $29.08 \%$ \\
\hline Gross profit & 2592 & 5881 & $26.89 \%$ \\
\hline
\end{tabular}

\subsection{Data collection}

Data collected to perform whole farm budget analysis for alternatives goat farming systems. The technical goat breed performance parameters such as milk yield, milking days duration, daily growth rate, number of kids born for each 100 Does were collected from Rumais Livestock Research Centers and from on farm trail experiment conducted on year 2005 at Batinah Region.

Market information such as milk and kid sale price, cost of inputs and other operation cost for each model were collected from Farmers and market survey. The study used Monte Carlo Simulation analysis to identified stochastic variables to be incorporated in the model such as yields, input cost, and output prices. The study also identified the probability distributions of the risky uncertain input variables and normal distribution is used to estimate Cumulative Distribution Function (CDF) of the output (NR) for each model.

The study performed Stochastic Efficiency with Respect to a Function (SERF) analysis to evaluate different policy and generates Certainty Equivalent (CEs) and ranking risky alternatives within different risk aversion level. The Certainty Equivalent (CEs) value used to calculate risk premium need to be paid to farmers for policy application and encouragement.

\subsection{Model Structure}

The modeling process began by defining inputs and parameters effecting goat breeding income and return. The goat breed performance parameters cost of operation and incomes affect each breed activities models obtained. The qualitative risk analysis used in this study to provide a high level of understanding of risks of goat breeding. Such analysis may increase attention of goat breeding advisers, forage grown policy at Batinah area and animal feed subsidy policy adviser to the top risks they need to manage effectively. In this analysis, we have investigated the economic viability of three goat breeds farming system, feed subsidy program and home grown forage under different risk aversion level. Six alternative production systems summarized as under : The main production systems under risk and uncertainty variables identified models were :

- Model (1) ShHNS - Shami goat breed, Home grown forage and No animal feed subsidy.

- Model (2) ShHS - Shami goat breed, Home grown forage and animal feed subsidy.

- Model (3) BaHNS - Batinah goat breed, Home grown forage and No animal feed subsidy.

- Model (4) BaHS - Batinah goat breed, Home grown forage and animal feed subsidy. 
- Model (5) ShPS - Shami goat breed, forage purchase and animal feed subsidy.

- Model (6) BaPS - Batinah goat breed, forage purchase and animal feed subsidy.

The simulation model is presented below :

$\mathrm{N}^{\sim} \mathrm{R}=\left({ }^{\sim} \mathrm{Ya}^{*}{ }^{\sim} \mathrm{Pa}+\mathrm{Yb}^{*} \sim \mathrm{Pb}+\mathrm{Ye}^{*} \mathrm{Pe}+\ldots \ldots ..\right)-\mathrm{FC}-\mathrm{V}^{\sim} \mathrm{C}$

\section{Where:}

$\mathrm{N}^{\sim} \mathrm{R}$ Probability distribution for net return.

־a Stochastic yield for Batinah or Shami milk

$\mathrm{Pa}$ Stochastic price for Batinah or Shami milk

$\mathrm{Yb}$ number of kids sold for Batinah or Shami (meat)

$\sim \mathrm{Pb}$ Stochastic price for Batinah or Shami live goat

Ye Yield for Batinah or Shami Does (meat)

Pe Price Batinah or Shami Does (meat)

FC Fixed cost for Batinah or Shami goat farming (Labour, medicine, housing, depreciation,... )

$\mathrm{V}^{\sim} \mathrm{C}$ Stochastic variable cost for Batinah or Shami goat farming (concentrate with or without subsidy, forage cost home grown or purchase,,... ).

\subsection{Stochastic Efficiency with Respect to a Function (SERF)}

Simulation model is used to investigate goat breed farming system and goat farming policy sustainability at Batinah Region. The goat farming system failure could be measured in financial terms of getting a negative Net Return (Hansen and Jones, 1996).

A stochastic efficiency model performed to compare the NR of three goat farming systems by forming six models. Stochastic efficiency with respect to a function (SERF) is used to rank the risky alternatives simultaneously with different risk aversion preferences. Risk Premium is also calculated by subtracting CE Certainty equivalent for less preferred goat farming alternative from dominant alternative. Given a utility function $\mathrm{u}(\cdot)$, a random wealth variable $\mathrm{X}$, and an initial level of wealth $\mathrm{w} 0$, the certainty equivalent is :

$\mathrm{CE}=\mathrm{u}-1\{\mathrm{E}[\mathrm{u}(\mathrm{X}+\mathrm{w} 0)]\}-\mathrm{w} 0$,

The risk premium measure the minimum amount need to be paid to farmers and decision maker to justify a switch from present goat farming system to other less risky alternative. The model simulated the costs and returns for keeping 100 Does breeding at one hectare of land. The Net Return is calculated and probability distributions generated by the simulation model. The model used to rank the best alternative policy across a full range of RACs. The study finally performed CE analysis to estimate premium price and subsidy should be given to farmers to keep their goats at a less risky farming system and utilize farm resources in a sustainable manner.

\subsection{Cost of Production and Margin Analysis}

\section{Result and Discussion}

The cost of production and margin analysis shows that Shami goat breed obtained the highest gross margin per farm. The gross margin per head of Shami breeds with forage home grown and No feed subsidy program increased by $127 \%$ compare to Batinah goat breed. In feed subsidy and forage purchase program Shami goat breed margin per head increased by $129 \%$ compare to Batinah goat breed. The feed subsidy program with forage grown increased gross margin by 15\% and 35\% for Shami and Batinah goat breed, respectively, Table (2). The policy analysis shows a multiple and integrated objectives between animal feed subsidy and permition of home grown forage policy and freezing one of these policies will affect goat farming net return sharply and high attention needs to be considered by policy advisers to avoid policies contradictions.

Table (2) : Cost of Production of Shami and Batinah Goat Breeds and Different Farming Policy- Rial Omani :

\begin{tabular}{|l|l|l|l|l|l|l|}
\hline Models & Model (1) & Model (2) & Model (3) & Model (4) & Model (5) & Model (6) \\
\hline Policy & ShHNS & ShHS & BaHNS & BaHS & ShPS & BaPS \\
\hline Concentrate Price & 135.80 & 116.70 & 135.80 & 116.70 & 116.70 & 116.70 \\
\hline Forage Price/ton & 40 & 40 & 40 & 40 & 80 & 80 \\
\hline Bucks Sale Revenue & 5015 & 5015 & 5200 & 5200 & 5015 & 5200 \\
\hline Does Sale Revenue & 3315 & 3315 & 3200 & 3200 & 3315 & 3200 \\
\hline Cull Adults 20\% & 600 & 600 & 700 & 700 & 600 & 700 \\
\hline Milk Value & 4848 & 4848 & 1532 & 1532 & 4848 & 1532 \\
\hline Manure Value & 186 & 186 & 186 & 186 & 186 & 186 \\
\hline Total Revenue & 13964 & 13964 & 10818 & 10818 & 13964 & 10818 \\
\hline Depreciation & 120 & 120 & 160 & 160 & 120 & 160 \\
\hline Gross Output & 13844 & 13844 & 10658 & 10658 & 13844 & 10658 \\
\hline
\end{tabular}




\begin{tabular}{|l|l|l|l|l|l|l|}
\hline & & & & & & \\
\hline Concentrate Cost & 6357 & 5462 & 6446 & 5539 & 5462 & 5539 \\
\hline Forage Cost & 936 & 937 & 950 & 950 & 1873 & 1899 \\
\hline Total Feed Cost & 7294 & 6398 & 7396 & 6489 & 7334 & 7438 \\
\hline & & & & & & \\
\hline Fixed Cost & 669 & 669 & 669 & 669 & 669 & 669 \\
\hline Total Production Cost & 7963 & 7067 & 8066 & 7158 & 8004 & 8107 \\
\hline Gross Margin & 5881 & 6776 & 2592 & 3500 & 5840 & 2551 \\
\hline Gross Margin/head & 58.808 & 67.765 & 25.923 & 35.005 & 58.402 & 25.510 \\
\hline
\end{tabular}

\subsection{Monte Carlo Simulation Models Run Results}

The study investigated the goat breed farming economic performance and sustainability and calculates Net Return by using experimental and farm trial data collected from Rumais Livestock Research Centers. The analysis shows the Modern Goat Farming i.e. (ShHS) Shami breed with forage home grown policy and feed subsidy and (ShPS) Shami breed with forage purchase and feed subsidy program are the most risk efficient farming system Figure $(2,3)$. The Traditional Goat Farming System i.e. (BaHNS) Batinah breed with forage home grown and No feed subsidy and (BaPS) Batinah breed with forage purchase and feed subsidy program are less risk efficient alternatives, Table $(3,4)$. However, this indicates that local breed improvement and introduction of high yield genetics breeds to the area is important for achieving goat farming sustainability and enhancing economic performance measurements.

The Coefficient on of Variation of the probability distribution of traditional system net return is high for (BaHNS) Batinah breed with forage home grown and No feed subsidy model and for (BaPS) Batinah breed with forage purchase and feed subsidy program, however this revealed that Traditional Goat Farming System is recognized as instability goat farming system and less risk efficient.

Batinah breed with forage home grown and feed subsidy program model (BaHS) show a $(-0.061)$ Skewness figure and indicates downside risk control, whereas, Shami breed with forage home grown and feed subsidy program (ShHS) shows upside risk control and positive high farm returns. Farmer at coastal area breeding Batinah goat with home grown forage and feed subsidy got a frequent small gain but few extreme losses.

Table (3) : Shami and Batinah Goat Farming Systems and Policies Net Return Summery Statistics :

\begin{tabular}{|l|l|l|l|l|l|l|}
\hline & \multicolumn{2}{l}{ Traditional Pasture Farming } & \multicolumn{2}{l}{ Coastal Area Farming } & \multicolumn{2}{c|}{ Modern Goat Farming } \\
\hline Models & BaHNS (3) & BaPS (6) & BaHS (4) & ShHNS (1) & ShPS (5) & ShHS (2) \\
\hline Mean & 1973 & 1690 & 4220 & 5390 & 5284 & 4889 \\
\hline SD & 13248 & 13194 & 13788 & 13989 & 13554 & 14008 \\
\hline CV & 671.62 & 780.53 & 326.75 & 259.55 & 256.53 & 286.51 \\
\hline Median & 1434 & 1179 & 4937 & 6041 & 5188 & 4170 \\
\hline Skewness & 0,114 & 0.000 & $-0,061$ & $-0,171$ & $-0,117$ & 0,181 \\
\hline Kurtosis & $-0,320$ & -0.362 & 0,037 & $-0,062$ & $-0,033$ & 0,280 \\
\hline Min & $(34634)$ & $(33976)$ & $(46458)$ & $(36931)$ & $(34172)$ & $(32599)$ \\
\hline Max & 36184 & 45328 & 40471 & 40050 & 43833 & 61321 \\
\hline Range & 70818 & 79304 & 86929 & 76981 & 78005 & 93920 \\
\hline Gross Margin $/ \mathrm{h}$ & 25.923 & 25.510 & 35.005 & 58.808 & 58.402 & 67.765 \\
\hline
\end{tabular}

\subsection{Goat breed farming systems and Cumulated Distribution Function Analysis}

To test goat farming systems and policies sustainability the Cumulated Distribution Function CDF graphs performed to illustrate the range and probabilities of net return value for different alternatives in Batinah Region. Due to CDF lines cross in the graph we could not ranked policies according to their sustainability by using first degree stochastic dominance, and Stochastic Efficiency with respect to a Function (SERF) is used to have a better ranking analysis. The analysis indicates Modern Goat Farming is the most risk efficient as its distribution line located on the right and preferred to those on the left line Traditional Goat Farming, Figure (1). 


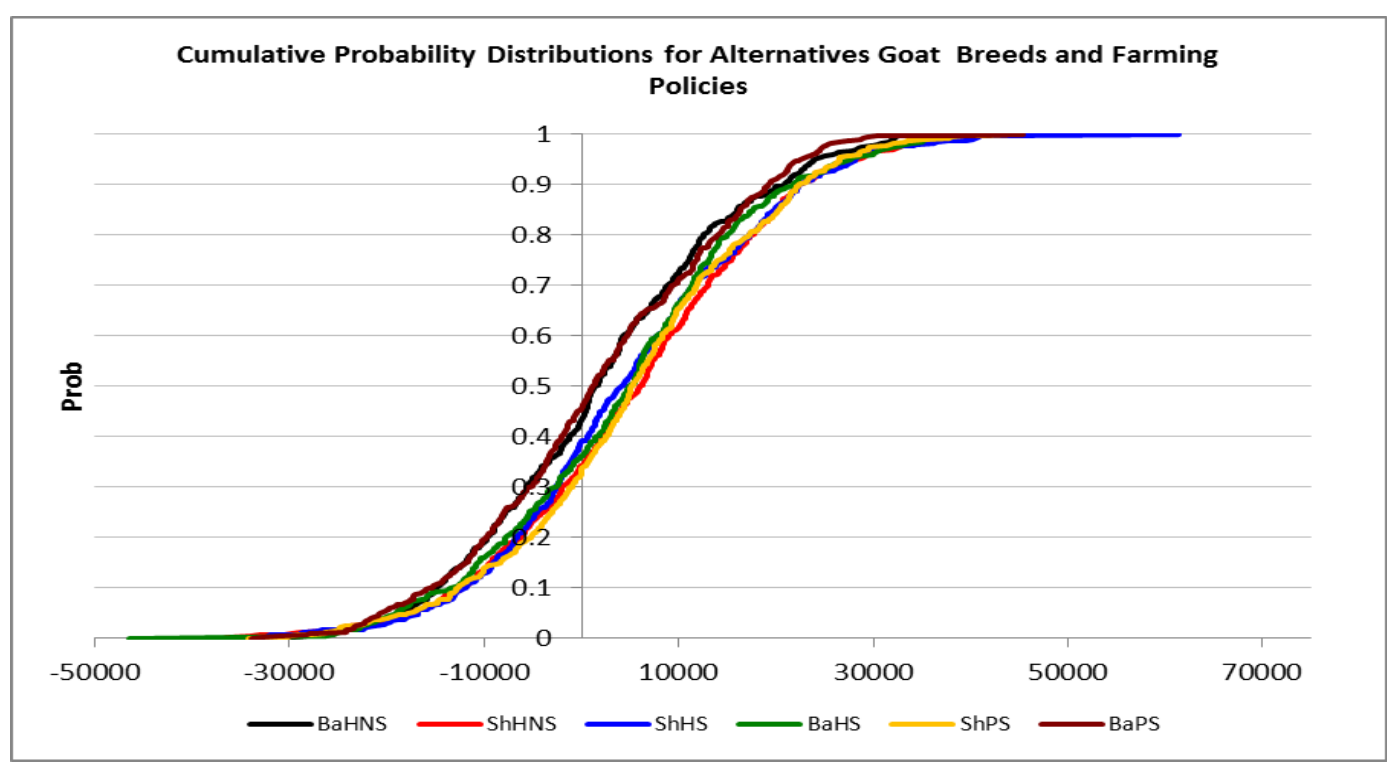

Figure (1) : Comparison of 6 CDF of NRs of Goats Breed and Alternative Farm Subsidy Policies.

\subsection{SERF Analysis and Certainly Equivalent}

The SERF method calls for calculating Certainly Equivalent CE values over a range of absolute risk aversion coefficients (ARACs). The ARAC represents a decision maker's degree of risk aversion. Decision makers are risk averse if ARAC $>0$, risk neutral or risk normal if $\mathrm{ARAC}=0$, and risk preferring if ARAC $<0$. The ARAC values used in this analysis ranged from (0.0) represent risk neutral to (0.2) represent moderately risk averse. Shami breed with home forage grown and No feed subsidy (ShHNS) model obtained Certainly Equivalent CE values of RO 5,389 followed by Shami breed forage purchase and with feed subsidy (ShPS) RO 5,283 at neutral risk aversion coefficient as shown in Figure (2) below. Batinah breed with No feed subsidy and home forage grown (BaHNS) and Batinah breed with forage purchase and feed subsidy (BaPS) are less risk efficient under risk neutral risk aversion and need to be improved by cross breed with risk efficient breeds. Analysis also indicates sufficient forage and grasses are important and providing grass to desert and mounting pasture goat husbandry farmers with a reasonable price is very essential, Figure (3).

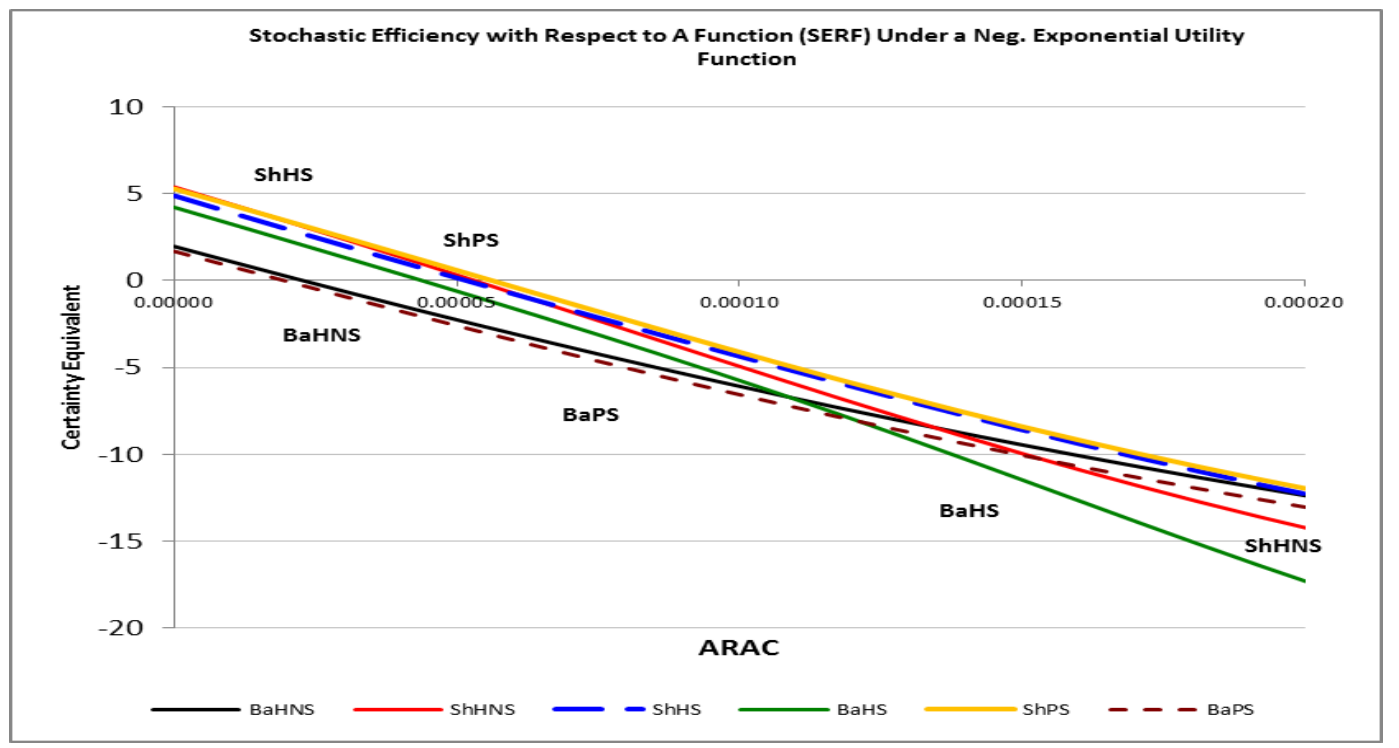

Figure (2) : Stochastic Efficiency with Respect to Function SERF for Alternative Goat Breeds and Policies.

\subsection{Certainly Equivalent and Assessment of Present Goat Farming}

Two models formed to present existing low nutrition goat farming systems i.e. (BaHNS) and (BaPS) models. The (BaHNS) model represent farmers at costal area at Sharqiyah and Batinah Regions and use supplementary animal feed such as grass, crop residuals, dates and dried sardines fish. The second model is 
(BaPS) represent the traditional mounting pasture goat husbandry system which use low nutritional grass quality of the pasture plants and purchase additional grasses and animal feed concentrates from their pocket.

Risk premiums analysis is calculated by using SIMETAR program to measure the value of present goat farming system and value of alternative supporting policies. Risk premium value is calculated by subtracting the $\mathrm{CE}$ of the less-preferred model from the CE value of the preferred alternative at different RAC level. Risk premium analysis can help policy maker to perform subsidy and incentive programs to encourage farmers to introduce high yield goat breed i.e. (Damascus Shami goats) and shift to a more sustainable goat farming system in mounting and desert area i.e. (ShPS) model Shami goat breed, forage purchase and animal feed subsidy program. Model (ShHS), Shami goat breed, home forage grown and animal feed subsidy program can be recommended to Coastal goat farming area as a sustainable goat farming system. The policy maker should control Rhodes Grass price to RO 80 per ton and avoid price increase to insure the effectiveness of this policy and model sustainability.

Risk premium price of RO 35.930 per Does is required to persuade farmers to shift from traditional goat farming i.e. (BaPS) model to high yield breed and modern goat farming system model (ShPS). Policy Makers need to pay RO 25.290 per Does to compensate farmers at semi-intensive coastal goat farming system to shift from (BaHS) to (BaPS) and stop growing Rhodes Grass at coastal area. The introduction of low water use forage and legumes in place of high water use crops and trees need to be encouraged to improve ecosystem resilience and economic viability. Different policies analysis and risk premium values can be obtained from Table (4) and Figure (3).

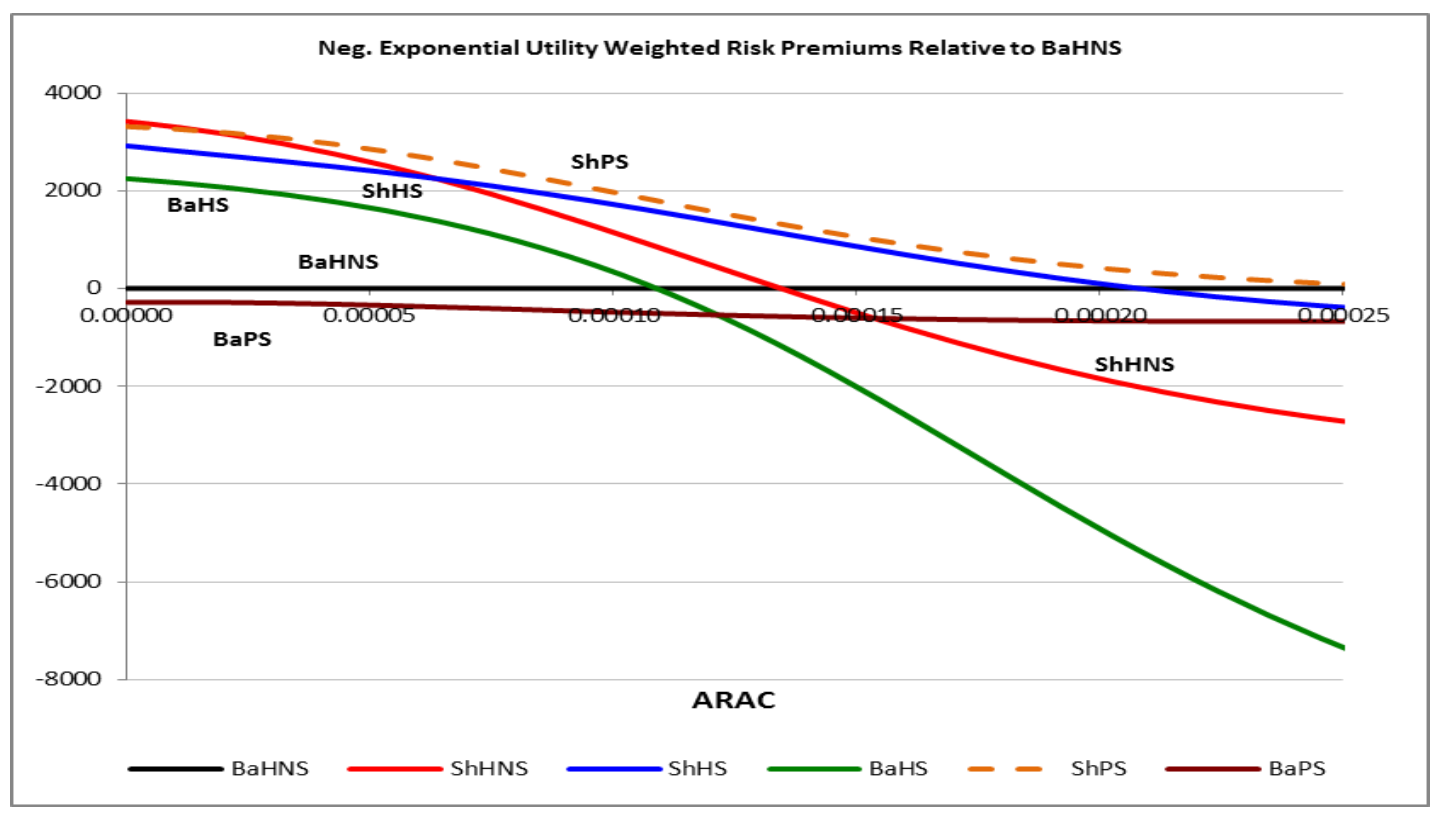

Figure (3) : Risk Premium relative to Batinah breed \& home grown forage, No feed subsidy program (BaHNS).

Table (4) show six goat farming systems models and identifies the relevant CEs value for each model. Farmers and Decision Maker can express their willing to exchange the preferred policy alternative according to their risk perception and risk aversion level. The Certainly Equivalent CE values in Table (4) indicates that Shami goat breed with forage purchase and animal feed subsidy program (ShPS) is the most sustainable and risk efficient goat breed farming under slight, normal and moderate risk aversion level. The result shows that Batinah goat breed with home grown forage and animal feed subsidy program (BaHS) is the $4^{\text {th }}$ risk efficient alternative at low and high level of ARAC and (BaPS) is the less risk efficient at a high level of ARAC as shown in Figure (2).

Table (4) : Ranking of Goat Breeds and Farming Policies by Risk Aversion using CE for NRs :

\begin{tabular}{|l|l|l|l|l|l|l|l|l|}
\hline Risk & Risk Neutral & \multicolumn{2}{|l|}{ Slightly Risk } & Normal Risk & \multicolumn{3}{l|}{ Moderate Risk } \\
\hline ARAC & 0.00000 & & 0.00002 & & 0.00003 & & 0.00004 & \\
\hline Rank & Alternative & CE & Alternative & CE & Alternative & CE & Alternative & CE \\
\hline 1 & ShHNS & 5389 & ShPS & 3307 & ShPS & 2304 & ShPS & 1294 \\
\hline & & & & & & & & \\
\hline 2 & ShPS & 5283 & ShHNS & 3272 & ShHNS & 2189 & ShHNS & 1093 \\
\hline & & & & & & & & \\
\hline 3 & ShHS & 4889 & ShHS & 2834 & ShHS & 1828 & ShHS & 833 \\
\hline & & & & & & & & \\
\hline
\end{tabular}




\begin{tabular}{|l|l|l|l|l|l|l|l|l|}
\hline 4 & BaHS & 4219 & BaHS & 2183 & BaHS & 1154 & BaHS & 116 \\
\hline 5 & & & & & & & & \\
\hline & BaHNS & 1972 & BaHNS & 128 & BaHNS & -773 & BaHNS & -1657 \\
\hline 6 & BaPS & 1690 & BaPS & -158 & BaPS & -1074 & BaPS & -1979 \\
\hline
\end{tabular}

\subsection{StopLight Analysis and Economic Viability of Goat Farming System}

The StopLight Chart analysis is performed to evaluate economic viability of goat farming policy. StopLight analysis can be used as good tool for ranking goat farming system and alternative policies and indicate the probability of getting favorable Net Return. Assuming each operation has risk-averse preferences, the optimal scenario is the one which has the highest probability of farm net return. The probability of achieving RO 5,000 Net Return is presented in green colour, whereas, goat farming policy probability of getting Net Return of RO 1,000 and lower is denoted in red colour, as shown in Figure (4) below.

Model (BaPS) Batinah goat farming with forage purchase and animal feed subsidy program got $50 \%$ probability of getting 1,000 Net Return and 39\% probability of getting RO 5,000 or more Net Return. Batinah goat breed with home grown forage and feed subsidy program (BaHS) reduce low income farmers percentage from $50 \%$ to $39 \%$ and increase the probability of getting high income farmers to $61 \%$. The analysis also shows that introduction of new high yield goat breed i.e. (Damascus Shami goats) will increase the probability of getting RO 5,000 NR from 39\% in (BaPS) to 51\% in (ShPS) and encourage farmers to move to forage purchase system. However, this may prove the important of feed subsidy for Batinah breed and forage is essential for Shami breed.

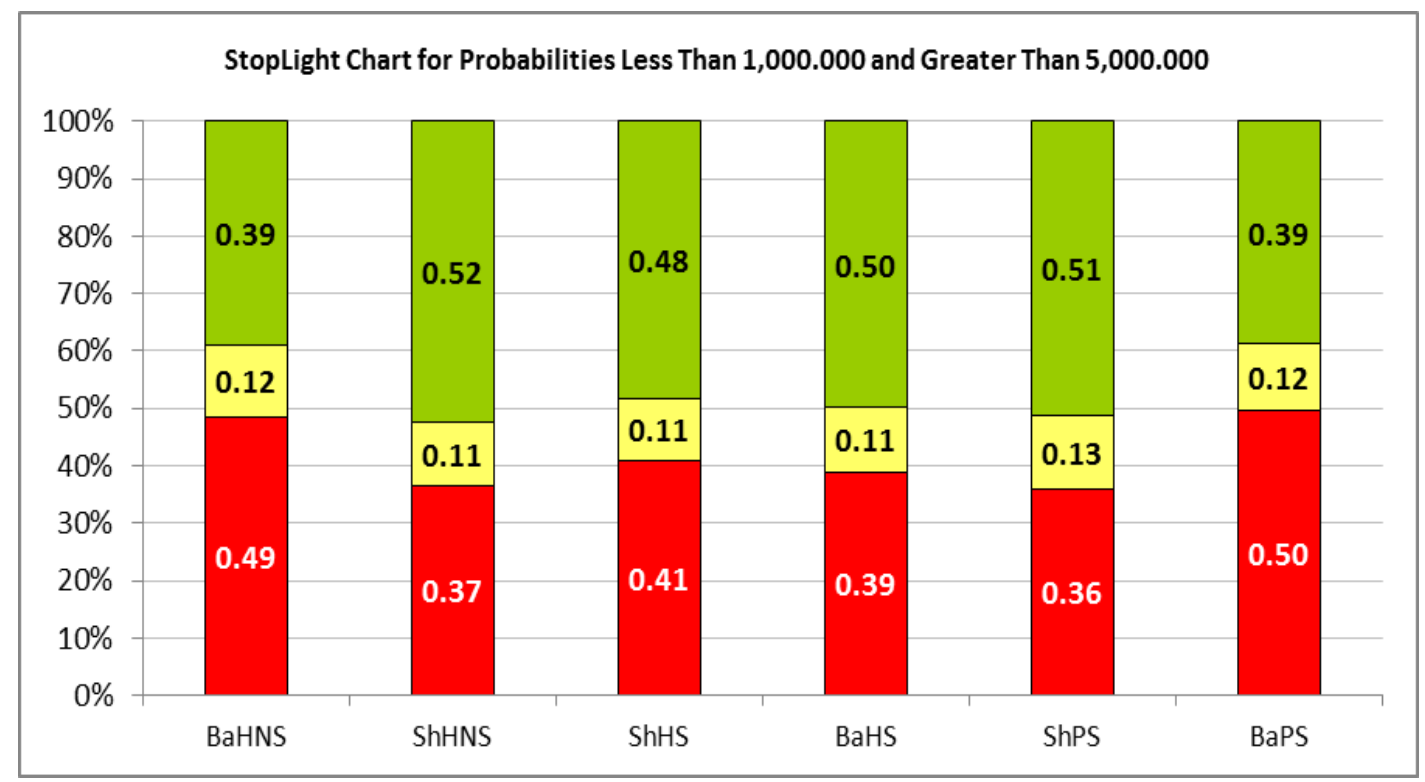

Figure (4) : Probability of Net Return Values for Shami , Batinah Goat Breeds and Different Farming Subsidy.

The study also indicates that Batinah and Sharqiyah Region farmers will benefit from improvement goat farming activities and crop diversification policy. Farm activities risk efficiency and sustainability will be enhanced by encouraging and motivation of goat farming system. Moreover, the water salinity problems can be solved by animal husbandry diversification and ecosystem resilience and economic benefits can be obtained.

\section{Conclusion}

The main task of this paper is to investigate goat farming systems risk efficiency and sustainability at different risk aversion level. Sustainable goat farming systems depend on two main factors. The first one is identifying sustainable goat breed within farm location area i.e. (Batinah Region) and the second is availability of institute supporting policies that understand farmers perception and risk aversion attitude. Accordingly this paper grouped the simulated models to three groups to represent animal feed subsidy program, forage and grass availability with cheap price and high yield genetic breed availability.

The traditional goat farming system at mounting and desert area has low income and need to be improved through animal feed subsidy program and provide grass with low cost. The genetic improvement is also required to encourage farmers to utilize their resources. The gross margin per head for (ShHNS) Shami breeds with forage home grown and No feed subsidy program increased by $127 \%$ compare to (BaHNS) Batinah 
goat breed. The genetic improvement contribution is high mainly at traditional and coastal goat farming systems.

In animal feed subsidy program, the Government Authority introduce subsidy program in year 2011 and reduce goat feed price by $14 \%$. Whoever, this feed subsidy program increased gross margin per head by $35 \%$ for Batinah goat breed and by $15 \%$ for Shami goat breed.

The forage and grass availability is essential and comparison between (BaHS) and (BaPS) shows that gross margin increased by 37\% if grasses available at farm. The gross margin in Shami goat breed increased by $15.6 \%$ which indicates the important of grasses to Batinah goat breed. The analysis shows that local Batinah breed face lower net return risk and Batinah breed with grass availability at home and feed subsidy program (BaHS) is downside risk control and got a frequent small gain but few extreme losses. The new goat breed introduced (Damascus Shami breed) with forage home grown and feed subsidy program is upside risk control and high positive farm returns is observed.

Modern Goat Farming i.e. (ShHS) Shami breed with forage home grown policy and feed subsidy and (ShPS) Shami breed with forage purchase and feed subsidy program are the most risk efficient farming system. The Traditional Goat Farming System i.e. (BaHNS) Batinah breed with forage home grown and No feed subsidy and (BaPS) Batinah breed with forage purchase and feed subsidy program are less risk efficient alternatives Batinah breed with No feed subsidy and home forage grown (BaHNS) and Batinah breed with forage purchase and feed subsidy (BaPS) are less risk efficient under risk neutral risk aversion and need to be improved by cross breed with risk efficient breeds. Analysis also indicates sufficient forage and grasses are important and providing grass to desert and mounting pasture goat husbandry farmers with a reasonable price is very essential.

Risk premium price of RO 35.930 per Does is required to persuade farmers to shift from traditional goat farming i.e. (BaPS) model to high yield breed and modern goat farming system model (ShPS). Policy Makers need to pay RO 25.290 per Does to compensate farmers at semi-intensive coastal goat farming system to shift from (BaHS) to (BaPS) and stop growing Rhodes Grass at coastal area Appropriate risk perception can be seen as an important factor for choosing an effective risk-coping strategy, because farmer that is not aware of the risks facing his goat farming clearly will not be able to manage them effectively. Drought in traditional mounting pasture system, Water shortage and salinity at coastal area and institutional risk connected with goat farming support are very important and need to be understood by policy makers for choosing an effective riskcoping strategy.

\section{Competing interests}

The author declared that the research was conducted in the absence of any commercial or financial relationships that could be construed as a potential conflict of interest.

\section{References}

[1]. Eva Schlecht, Osman Mahgoub, Andrew Palfreman, (2009), "Social and economic aspects of crop and livestock husbandry, and development of sustainable management options for Al Jabal al Akhdar oases agriculture in Oman". Organic Plant Production and Agroecosystems Research in the Tropics and Subtropics, University of Kassel, Germany and Department of Agricultural Economics and Rural Studies, College of Agriculture and Marine Science, Sultan Qaboos University, Muscat, Oman.

[2]. Gregory K. Regier, Timothy J.Dalton, Jeffery R. Williams (2012) “ Impact of Genetically Modified Maze on Smallholder Risk in South Africa" AgBio Forum, 15(3): 328-336.

[3]. Hardaker J. B., Richardson J. W., Lien G, Schumann K D. (2004a) " Stochastic efficiency analysis with risk aversion bounds : a simplified approach" Australian Journal of Agricultural and Resource Economics 48:253-270.

[4]. Hardaker J. B., Huirne, R. B.M., Anderson, J. R., Lien G, (2004b) " Coping with Risk in Agriculture", second ed. CABI Publishing Wallingford.

[5]. Hansen J.W. and Jones J.W. (1996) " A system framework for characterizing farm sustainability " Agriculture Systems , Vol. 51, PP. 185-201.

[6]. Irene Tzouramani, Alexandra Sintori, Angelos Liontakis, Pavlos Karanikolas, George Alexopoulos (2011), "An assessment of the economic performance of organic dairy sheep farming in Greece". Livestock Science 141 (2011) 136-142.

[7]. J. W. Richardson \& J. L. Outlaw (2008), "Ranking risky alternatives: innovations in subjective utility analysis" WIT Transactions on Information and Communication, Vol 39, Risk Analysis VI, WIT Press. ISSN 1743-3517 (on-line) - doi:10.2495/RISK080231

[8]. Kheiry Hassan M. Ishag (2015), "Risk Management Strategies of Desert Farming at Najed in Sultanate of Oman" Journal of Sustainable Development - Vol. 8, No. 2 February 2015, ISSN 1913-9063, DOI:10.5539/jsd.v8n2pl.

[9]. Lien G., Hardaker J. B. and Flaten O. (2007), "Risk and economic sustainability of crop farming systems" Agricultural Systems, volume 94, issue 2:541-552. DOI: 10.1016/j.agsy.2007.01.006

[10]. MAF (2014), "Second Country report on the state of Farm Animal Genetic resources".

[11]. Zaibet, L., Dharmapala, P.S., Boughanmi, H., Maghoub, O., Al-Marshudi, A. (2004). Social changes, economic performance and development: the case of goat production in Oman. Small Ruminant Research 54, 131-140. 